\title{
Legal Issues in Free Trade Agreements Xie Fei
}

Faculty of Law, University of Montreal, Montreal, QC, CA

timyfei@gamil.com

Keywords: China; Bilateral Free Trade Agreement; Trade in Goods; IP Provisions.

\begin{abstract}
Free Trade Agreement, especially Bilateral FTA, has become a solution to the improve international trade situation since the suspension of Doha Round, and it is adopted by many countries. As one the biggest developing country, China has developed trading relationships with many countries by FTAs in order to prompt the scale and content of cooperation. However, there are several problems located inside of those FTAs. Therefore, it will be generated that, the first, what is the legal framework of FTA, and, the second, what are those several problems in FTAs between China and the other parties. Finally, possible solutions and suggestions will be addressed and prompted to talk about the influence of regional trade arrangement to globalization.
\end{abstract}

\section{自由贸易协定中的法律问题}

\author{
解非 \\ 蒙特利尔大学法学院, 蒙特利尔, 魁北克, 加拿大 \\ timyfei@gamil.com
}

关键词: 中国；双边自由贸易协定；货物贸易；知识产权条款

中文摘要. 自多哈谈判回合陷入进退两难的境地, 自由贸易协定, 尤其是双边自由贸易协定, 成为了许多国家的解决问题的首选, 作为发展大国, 中国亦缔结了多个双边自由贸易协定, 不断扩大合作的范围和补充合作的内容。但是，自由贸易协定中存在着诸多问题，因此，文 章通过实例来分析自由贸易协定的法律框架、中国双边自由贸易协定中的法律问题以及提出 相应的潜在的解决方法或者建议, 同时, 将进一步讨论中国缔结的双边自由贸易协定, 对世 界经济发展的影响。

\section{1. 法律框架}

由于贸易便利化的发展受阻，自由贸易协定（Free Trade Agreements，以下均简称 FTA） 因其独到的优势, 成为了各国在发展自由贸易的首选, 而双边 FTA 的研究也随之进行的如火 如茶。作为一个从根本上与关贸总协定 (以下简称GATT) 的 “非歧视原则” 相冲突的法律工 具, 它的存在, 是整个 WTO 框架的一个例外。事实上, WTO 不仅承认双边 FTA 的存在, 而且 除了 GATT 第 5 和 24 条以外, GATT 还在 1976 年设立了授权条款以协调 FTA 和 WTO 的关系。

GATT 第 24 条是双边 FTA 得以成立的最重要的条款, 从根本上承认了双边 FTA 的法律地 位。GATT 第 24 条第五款允许 WTO 的成员国之间以协议的方式缔结关税同盟、自由贸易区等 关系，同时允许成员国之间签订以缔结关税同盟、自由贸易区等关系为目的的临时协定，实 践区域贸易安排。GATT 第 5 条针对贸易便利化而制订, 主要涉及过境自由, 双边 FTA 则是在 贸易便利化无法继续的情况下各国采取的一项替代方式来应用 GATT 第 5 条的相关条款。内 
容涵盖过境运输定义、便捷过境权利、关税免除待遇等。整体来看，第 5 条是为了保障贸易 自由过境而制定的，围绕着这个目的，赋予了过境人员两项权利，一是选择最便捷途径过境 的权利, 二是免除过境关税并且享受平等行政收费待遇的权利。授权条款则授权发达国家给 予发展中国家优惠差别待遇，从一定程度上推动了双边贸易和区域性贸易安排的进行。

\section{2. 中国双边自由贸易协定的主要法律问题}

\section{1 货物贸易中的特殊保护条款}

由于 GATT 第 24 条的存在，使得双边 FTA 可以不受非歧视原则和最惠国条款的调控，产 生出以特殊保护条款为代表的不应长时间存在成为常态的非常态条款。

以中国和新西兰所缔结的双边 FTA 为例。在中一新双边 FTA 中，中方保留了农产品的顺 畅进出口的权利, 限制新方每年的乳制品进口量, 以此来保护中方相关产业的安全。特殊保 护条款的存在, 是人为降低贸易自由化程度的条款, 有违双边 FTA 加强贸易自由化的本意, 虽然能够有效的保护国内相关产业, 但是从长远发展的角度来看, 也阻碍了相关产业和国家 对外贸易的发展。

保护效果只是暂时的, 解决方法还是要提高产品质量。如果没有特殊保护条款, 中新之 间，关税大幅降低，甚至于实现零关税，中国的乳制品行业必定受到极大的冲击。由于 “毒 奶粉” 等事件的出现, 导致国产乳制品的信用大大降低, 很多购买者, 尤其是为老人和贞儿 购买的人群，更倾向于以更高的价格来购买新西兰乳制品，不愿也不敢购买国产乳制品，更 不用说将我国的乳制品出口海外。这一现象反映出我国不论在乳制品行业的的监管上出现的 极大漏洞，同时也反映出在货物贸易方面，一味采取保护措施不是长远的计划。

所以，特殊保护条款虽然在短期能够起到保护国内产业的作用，但由于它阻碍了贸易自 由化, 人为的加强了贸易壁垒, 始终不是长远的应对方法。最好的应对方法, 是从根本上解 决产品质量问题，在我国，存在产品质量问题的不仅仅是乳制品，电子产品、服装产业、烟 花行业等等很多产业均存在着或多或少的问题，而经济全球化已经成为一个现实，贸易便利 化程度会不断提高, 我国货物贸易中所存在的问题迟早会爆发。提高产品质量, 直面国际竞 争的冲击，才是解决货物贸易问题的核心。

\section{2 服务贸易和投资中法律系统发展程度的不同}

中国和东盟 10 国在 2007 年初签订了《服务贸易协议》，该协议要求中方自 2007 年 7 月 1 日起，向东盟开放我国建筑、环保、运输、体育和商务 5 个部门及其 26 个分部门, 而东盟 也在医疗、金融、旅游、教育等多个方面对我国做出了开放承诺。虽然承诺的做出, 给双方 带来机遇，但是由于法律系统发展程度，影响进一步发展。

中国和东盟之间服务贸易的首要问题则是服务贸易体制的问题，中国的服务贸易发展起 步晚, 所以其标准相较东盟要落后一些, 而且在划分方式、统计结构等均与东盟不一样, 而 服务贸易的因服务业涉及面广、种类复杂的特点，导致数据收集上有相当大的困难，没有相 应的参考数据, 就无法更科学的建立服务贸易机制, 进一步发展和完善我国和东盟之间的服 务贸易。

问题表现在法律上，则表现为我国的国内立法还不完善。虽然东盟在 2007 年便对我国 做出了开放 “旅游” 行业的承诺, 但是我国直到 2013 年 10 月份才正式实施《旅游法》，而 在这期间，不论是本国的服务向东盟流出，还是东盟的服务向我国流入，均存在着不小的压 力。不难想到, 在当时没有正式法律的几年, 服务提供者和消费者难以熟悉杂乱的行政规定, 同时在需要资格认证的行业，服务提供者由于较难具备对方国家的行业资质而降低了服务贸 易的流动。其次，由于我国的至今还未建立服务贸易法，而且相关问题的解决未形成成熟的 法律体系，会在不同的法律部门间形成冲突，这在无形中增强了服务贸易困难。 
当然除了上述问题之外，我国的对外服务贸易还会存在着空间距离成本、他国制度障碍、 文化阻隔、海关监管问题等多项困难, 这些问题会随着服务贸易的不断发展和交流而逐渐解 决。

类似的问题同样存在与投资自由化中。

中国和白俄罗斯之间的投资往来，从最初的货物贸易，已经发展到今天的深度经贸合作， 甚至于中方已经可以投资到白俄罗斯首都的明斯克机场的改造项目上，但中白之间投资方面 的法律发展相差甚远。白俄罗斯拥有成熟的投资法律体系, 设立《投资法典》，而且围绕法 律设立由总统直属的外资协商委员会。我国至今还未有相关法律, 只有在 2015 年商务部就

《投资法》的草案公开征求意见, 即还未制定出草案。其次, 由于中白之间路途遥远, 导致 中白之间的贸易成本高, 甚至于某些中国商品从中国运输到白俄罗斯的成本, 比白俄罗斯从 苏联进口同样产品的成本还高, 这就在极大程度上限制了中白之间的贸易规模, 从而使投资 行业不断减少，投资压力大，导致投资自由化产生问题。

\section{3 知识产权相关条款纳入FTA的困难}

将知识产权条款纳入 FTA 的困难主要有两个方面, 一是知识产权的保护是具有领域性的, 即在一国申请知识产权, 只能在一国领域内收到合法保护。而将知识产权纳入 FTA 之后, 意 味着一国的合法知识产权将在缔约国产生效力以及受到保护, 从而产生出诸如知识产权资格, 即一国知产是否达到缔约国知产的基本标注、知识产权冲突, 即一国知产是否已经在缔约国 获取知产资格并受到合法保护等问题, 甚至一国知产在他国受到保护, 维持知产所必须的费 用该如何认定也是一个棘手的问题。

另一方面，知识产权在缔约国应用，可以被认定为是一种特殊的 “投资”，将知产投资 到缔约国, 收取应得的使用费或者直接的货物销售费, 甚至是侵犯知产的侵权赔偿。而成为 困难之处则在于, 与知产相关商业行为的所有内容, 均应在 FTA 中体现, 并在缔约国协商之 后进行规定。

第一个将知识产权条款纳入多边合约的是 1995 年的知识产权协定 (TRIPS, Agreement on Trade-Related Aspects of Intellectual Property Rights），而第一个将知产条款纳 入区域贸易安排的则是 1994 年的北美自由贸易协定（NAFTA, North American Free Trade Agreement）, 知识产权条款的发展程度相对年轻, 未有很多别出心裁的相关条款。相比之下, 较可能的解决方式便是在 FTA 中协定承认对方国家的知产, 当出现纠纷的时候, 依各自本国 法来解决问题。

\section{3. 中国签署的双边自由贸易协定对世界经济发展的意义}

中国自本世纪初加入 WTO 开始, 便一直以倡导多边贸易体制、缓和多哈僵局的姿态出现 在世界舞台上。多边贸易的前进步伐中止在 2006 年, 取而代之的则是以双边自由贸易为主 的区域性贸易安排。我国双边 FTA 的起步比较晚, 但是我国在对待双边 FTA 的态度正确, 采 取了符合我国国情同时贴近世界经济发展的战略, 是我国在新一轮的经济发展浪潮中处于领 先的地位。

根据世界银行发布的统计数据, 自己攵革开放至今, 中国 GDP 的平均增长速率接近 $10 \%$ 每 年, 而中国 GDP 每年对全世界经济的贡献超过 13\%, 而在 2010 年至 2012 年的三年中, 中国 的经济总量占同期世界经济总量的 25\%，而 2008 年到 2012 年的这段时间，正是以美国次贷 危机为核心原因的经济危机的复苏期, 从数据中可以看到, 中国的经济增长, 对全世界都有 着深远的影响, 就近来说, 在 2008 年到 2012 年这段时间, 中国在世界经济危机的复苏中必 定起到了不可忽视的作用。而长远看来, 则会发现, 中国经济的增长, 带动着世界经济中心 的转移以及世界经济重心的构建, 在 2010 至 2012 年间, 中国经济对世界经济的贡献量超过 
美国的贡献量, 成为了世界第一, 与此同时, 中美之间在经济上的排位上的互换, 带来的是 经济中心向东亚移动，同时中国也将成为世界各国构建贸易关系的重点之一。

自本世纪以来，中国已经和 22 个国家、地区建立了双边 FTA，而这一段时间正是中国经 济飞跃发展的 10 年，不得不承认的是，中国经济的飞速增长，双边自由贸易在其中所起到 的作用是重要的。中国签署的双边 FTA, 不仅仅对中国的经济发展产生了重大的影响, 更是 对世界经济发展做出了不小的贡献。中国已经俨然成为了最重要的经济大国之一, 而且中国 的贸易规模之大，更可以让中国成为贸易大国之一，而中国签署的双边 FTA，使世界的贸易 在中国汇聚，加强了国际间的贸易交流，加快了世界金融的速度，推动世界经济发展。

随着中国不断的缔结双边 FTA，拥有越来越多的成功案例，会有越来越多的国家加入到 建立双边贸易关系的队伍中。所以，中国成功的缔结双边 FTA，其所拥有的影响范围不止对 国内经济的影响, 对世界经济的潜在促进意义是不容小觑的。

反观区域性经贸合作，双边 FTA 所能起到的作用更加明显。举例来说，亚太地区的经贸 合作就是以双边 FTA 为基础和主要内容的, 虽然亚太地区有 APEC 的存在, 但是 APEC 由于是 多边谈判的成果, 其发展程度还有待提高, 亚太地区的经济一体化进程, 还需要不断缔结双 边 FTA 来推动，同时依靠不同国家之间的双边 FTA 的纵横交错，构架起区域经贸合作的框架。 中国作为亚太地区国家之一，尤其是国际上的经济、贸易大国，所建立的双边自由贸易关系 众多, 在大力推动亚太地区经贸合作发展的同时，也会将亚太地区的合作成果向世界展示， 并将亚太地区推向全球经济发展潮流。

\section{Reference}

[1] A, Hongwei. Research on Legal Problems of Service Trade in China-ASEAN Free Trade Area, Hefei: Anhui University, 2014.

[2] A, Zhaguha. Research on Bilateral Free Trade Agreement, Chongqing: Southwest University of Political Science and Law, 2008.

[3] China and Chile Signing Free Trade Agreement, China's Foreign Trade: English Version, 2010, vol.21, pp.11-11, 2005.

[4] C, Hongbo. Theoretical Reconstruction and Empirical Study of Bilateral Free Trade Agreements, Xiamen: Xiamen University, 2009.

[5] H, Lu. Economic and Trade Relations between China and Belarus: Status Quo, Problems and Countermeasures, Russia Central Asia and Eastern Europe Market, vol.6, pp. 85-125, 2013.

[6] L, Lusha. Economic Effect Analysis of China-New Zealand Bilateral Free Trade Area, Beijing: China University of Political Science, 2010.

[7] P, Li. The legal thinking mode, basis and framework of free trade zone, Political Forum (Journal of China University of Political Science and Law), vol.23, pp. 154-160, 2001.

[8] T, Smirnova. Economic Effect Analysis of China's Belarus Free Trade Zone, Chongqing: Chongqing University, 2012.

[9] Z, Chunhong. Bilateral Free Trade Agreements and China's Economic Development: An Empirical Analysis Based on Economic Growth and Employment Effect, World Economic and Political Forum, vol.6, pp. 26-30, 2005.

[10]Z, Jinping and Hu Jiangyun, The Impact of China's Development on the World Economy, Managing the World, vol.10, pp. 1-16, 2014. 